\title{
Particle removal process during application of impinging dry ice jet
}

$\operatorname{AUTHOR}(\mathrm{S})$ :

Liu, Yi-Hung; Hirama, Daisuke; Matsusaka, Shuji

CITATION:

Liu, Yi-Hung ...[et al]. Particle removal process during application of impinging dry ice jet. Powder Technology 2012, 217: 607-613

ISSUE DATE:

2012-02

URL:

http://hdl.handle.net/2433/152427

RIGHT:

(c) 2011 Elsevier B.V.; This is not the published version. Please cite only the published version.; この論文は出版社版でありません。引用の際に は出版社版をご確認ご利用ください。 


\title{
Particle removal process during application of impinging dry ice jet
}

\author{
Yi-Hung Liu, Daisuke Hirama, and Shuji Matsusaka* \\ Department of Chemical Engineering, Kyoto University, Kyoto 615-8510, Japan
}

*Corresponding Author's E-mail: matsu@cheme.kyoto-u.ac.jp

Keywords: Dry ice jet; Removal efficiency; Impact; Fine particle; Agglomerate

\begin{abstract}
In this study, we have investigated the application of dry ice blasting to remove fine particles adhering to surfaces and examined the removal process. The removal efficiency, area, and frequency have been analyzed using images captured with a high-speed microscope camera. In addition, the temperature of the dry ice jet has been measured in order to evaluate the dry ice particles and their effects on the particle removal process. The removal processes due to the impacts of primary dry ice particles and their agglomerates occurred in two stages corresponding to slow and rapid particle removals. High removal efficiency was achieved when the impacts of the agglomerates were dominant during the particle removal at approximately $-70{ }^{\circ} \mathrm{C}$. Furthermore, we have investigated the effects of the jet flow rate on the removal area and frequency and proposed a system parameter to determine the optimum jet flow rate for efficient particle removal.
\end{abstract}




\section{Introduction}

In industrial manufacturing, surface cleaning is crucial because contaminants on the surfaces of products degrade production quality and reduce yields; for example, fine particles deposited during manufacturing processes for electronic devices typically cause many defects. However, it is not easy to perform surface cleaning for fine particles because the adhesion force tends to be larger than the separation force, which makes their removal difficult. Today, pioneering industries are rapidly producing technical innovations, and high-efficiency cleaning methods must be developed to meet their requirements; in addition, such cleaning methods must also satisfy the increasing environmental concerns related to industrial processes.

Cleaning methods can be primarily divided into two categories — wet and dry cleaning that employ liquid and gaseous media, respectively. Wet cleaning exhibits very good cleaning performance and is popular in industries. However, environmentally harmful chemical additives such as acids are often used to enhance the wet cleaning performance. Moreover, drying processes are required after wet cleaning and water processing is required before discharging or recycling; this increases the energy and cost consumptions. Hence, alternative effective, environment-friendly, and economical cleaning methods must be established.

A popular dry cleaning method involves the application of the aerodynamic effect-air jets are used for the removal of fine particles from surfaces. Many studies on such particle removal procedures have been previously reported. Further, in order to explain the time course of particle removal efficiency, Masuda et al. [1] proposed a model that assumed that the removal flux is proportional to the number of particles whose adhesion force is smaller than the separation force. Otani et al. [2, 3] showed that consecutive pulse air jets are effective for particle removal. Gotoh et al. [4-6] discussed the effects of surface material, contaminant particle sizes, and relative humidity on the removal efficiency. In addition to the abovementioned cleaning systems, a translating gas jet that can be used to avoid the transient effects associated with jet startups was introduced by Smedley [7, 8].

Although air-jet dry cleaning is a simple and convenient process, the removal efficiency for smaller particles is limited. In the case of smaller particles, the area exposed to the air flowing over 
the surface is small, and consequently, they cannot be easily removed by the aerodynamic effect. To overcome this difficulty, Hoenig [9] demonstrated that a cleaning system using the flow of a soft substance over the surface can be employed to remove smaller particles. Carbon dioxide is the optimum soft substance because it is available under exceptionally clean conditions and is less costly and toxic. Moreover, secondary contamination problems do not occur after cleaning because dry ice will eventually sublimate under room conditions.

A jet flow containing dry ice particles can be produced by expanding liquid carbon dioxide by employing the Joule-Thomson process. Since the aerodynamic drag forces in stagnant regions in impinging jet flows are weak, the particles adhering to the surface cannot be removed easily. However, they can be effectively removed by the collision of dry ice particles, which provides sufficient momentum transfer. Dry ice blasting, i.e., the operations of gas-solid two-phase jet flows of gaseous carbon dioxide and dry ice particles, exhibits good performance for the removal of particulate contaminants and organic residues (Sherman [10]).

Jackson and Carver [11] summarized several possible removal mechanisms of dry ice blasting as follows: (i) kinetic separation based on the momentum transfer from dry ice particles to contaminants, (ii) aerodynamic drag separation, (iii) chemical separation caused by the dissolution of residues into liquid carbon dioxide, and (iv) electrostatic separation caused by the movement of the contaminants combined with charged dry ice particles. The kinetic and aerodynamic drag separations have been investigated by considering the moment of forces acting on a particle adhering to a surface (Kousaka et al. [12]; Wang [13]; Tsai et al. [14]; Matsusaka and Masuda [15]; Adhiwidjaja et al. [16]; Theerachaisupakij et al. [17]). Toscano and Ahmadi [18] investigated the particle removal mechanisms in dry ice blasting by introducing a moment balance model (rolling detachment model) and a force balance model (sliding detachment model). They concluded that the critical removal velocity necessary for impact-rolling removal is considerably lower than that for sliding removal. However, the sliding removal can also be effective for the removal of irregular particles (Banerjee and Campbell [19]). 
The size and shape of dry ice particles can be controlled by varying the conditions such as temperature and pressure. Swain et al. [20] installed a thermally insulated chamber at the end of an expansion nozzle to prepare agglomerates of dry ice particles. Agglomerated particles are useful in dry ice blasting because they do not sublimate as rapidly as small particles, and larger particles have larger kinetic energies. Liu et al. [21] investigated the agglomeration process of dry ice particles by analyzing the size and particle velocity of the ejected agglomerates. The agglomeration process was influenced by the temperature of the dry ice jet, and hence, the results of the temperature variation profiles of dry ice jets were used to explain the time course of the removal efficiency of particles with different diameters [22]. Furthermore, the ideal impact effects of a dry ice particle were investigated using monosized particulate contaminants, such as spherical latex particles, that were sparsely deposited on surfaces. However, the removal process of powder particles having a size distribution is still unclear.

In this paper, we describe our investigations into the removal process of powder particles having a size distribution using an impinging dry ice jet. The time course of the particle removal efficiency is quantitatively analyzed, and the effects of jet temperature on the removal efficiency are discussed. Furthermore, the particle removal area caused by dry ice impacts and removal frequencies are evaluated.

\section{Material and methods}

First, powder particles were dispersed and deposited on a test plate $(76 \times 26 \mathrm{~mm}$; 1-mm thick transparent glass), and subsequently, experiments were conducted to remove them by dry ice blasting. Note that the test plate was covered with a large number of powder particles in order to properly observe the removal process.

\subsection{Deposition of particulate contaminants}

Figure 1 shows a schematic diagram of the experimental apparatus used to deposit the powder particles. The test plate was placed on a metal mesh in a cylindrical vessel. Spherical alumina particles with a mass median diameter of $3 \mu \mathrm{m}$ and geometric standard deviation of 1.4 were dispersed for $1 \mathrm{~s}$ 
using an ejector. To control the air flow in the vessel, secondary air was introduced. The amount of particles deposited on the test plate was controlled by the air flow condition.

\subsection{Removal of particulate contaminants}

Figure 2 shows a schematic diagram of the experimental apparatus to remove the powder particles from the test plate surface by dry ice blasting. The dry ice jet was produced by expanding high-purity liquid carbon dioxide. A flexible hose made of stainless steel $-2 \mathrm{~m}$ in length and $15 \mathrm{~mm}$ in inner diameter-was connected to a high-pressure carbon dioxide cylinder. A needle valve was installed at the end of the hose in order to adjust the flow rate of the dry ice jet. A pressure gauge was also installed at the inlet of the needle valve in order to measure the inner pressure of the liquid carbon dioxide. The pressure measured in the experiments was approximately $5.5 \mathrm{MPa}$. To reduce heat transfers between the environment and equipment, the flexible hose and needle valve were thermally insulated. Further, to produce agglomerated dry ice particles, a 50-mm-long acrylonitrile-butadienestyrene (ABS) tube with 6-mm inner diameter was installed at the end of the needle valve. Agglomerated dry ice particles ejected from the tube with the carbon dioxide gas were directed toward the test plate. The angle of incidence of the dry ice jet against the surface was $\pi / 4$ radian, and the distance from the tip of the tube to the test plate was $20 \mathrm{~mm}$ in the axial direction.

To measure the temperature of the impinging dry ice jet, a temperature sensor was installed around the stagnant point. Further, the particle removal process was observed from behind the test plate using a high-speed microscope camera (Fastcam-Max, Photron Ltd.). The frame rate in the experiments was 250 or $500 \mathrm{fps}$. All the experiments were conducted at $20 \pm 2{ }^{\circ} \mathrm{C}$, and the relative humidity was controlled at $20-40 \%$ to avoid disturbances caused by liquid bridge forces.

\subsection{Analysis method}

To quantitatively analyze the particle removal process, particle removal efficiency, removal area, and removal frequency were obtained from the images captured by the high-speed microscope camera. The particle removal efficiency was determined by two methods-digital counting of the number of particles remaining on the surface and conducting measurements of the image brightness. The latter method was used in cases where digital counting was difficult, for example, when the surface was 
completely covered with the powder particles. The removal area caused by a dry ice impact was determined from the equivalent circle diameter. The removal frequency was determined from the variations in the removal efficiency at intervals of $2 \mathrm{~ms}$.

\section{Results and discussion}

\subsection{Particle removal efficiency}

Figure 3 shows micrographs of the particles on the test plate during dry ice blasting. When the jet flow rate was $1.4 \mathrm{~g} / \mathrm{s}$, most of the particles remained on the surface for approximately $8 \mathrm{~s}$ after the experiment began and were then almost completely removed within $0.2 \mathrm{~s}$ (Fig. 3a). When the flow rate was $4.9 \mathrm{~g} / \mathrm{s}, 20 \%$ of the particles were removed in the first $3 \mathrm{~s}$, and the remaining particles were removed within $0.05 \mathrm{~s}$ (Fig. 3b). These microscopic observations indicate that rapid particle removal began with a time delay that decreased as the flow rate increased. The dry ice particles ejected from the tube can be visually observed after approximately $8 \mathrm{~s}$ and $3 \mathrm{~s}$ for jet flow rates of $1.4 \mathrm{~g} / \mathrm{s}$ and 4.9 $\mathrm{g} / \mathrm{s}$, respectively. The rapid particle removal is probably caused by the visible dry ice particles.

Figure 4 shows the time courses of particle removal efficiency as a parameter of the jet flow rate. These results were obtained after digitally counting the number of particles remaining on the surface. When the jet flow rate was more than $2.2 \mathrm{~g} / \mathrm{s}$, the removal efficiency gradually increased with elapsed time and rapidly increased after a certain time was exceeded. Further, the maximum removal efficiency increased while the time needed to reach the maximum removal efficiency decreased as the jet flow rate increased; this happened because the separation force acting on the particles adhering to the test plate increased with the mass flow rate. Figure 4 also shows that the removal process comprises two stages I and II corresponding to slow and rapid particle removals, respectively.

\subsection{Theoretical analysis for slow removal stage}

The particles are removed from the surface when the separation force overcomes the adhesion force between the particles and surface. However, the adhesion force of each particle is not constant, and hence, the particle removal efficiency depends on the adhesion force distribution. It is noteworthy that the separation force caused by the dry ice blasting has temporal and special variations. 
Furthermore, the particle removal flux is proportional to the number density of the removable particles; therefore, the particle removal flux can be expressed as follows (Eq. 1):

$$
\frac{-d N}{d t}=\frac{N-N_{\mathrm{u}}}{\tau},
$$

where $N$ is the total number density of particles adhering to the surface; $N_{\mathrm{u}}$, the number density of unremovable particles whose adhesion force is larger than the separation force; $t$, the elapsed time; and $\tau$, a time constant. The analytical solution of Eq. (1) under the initial condition $N=N_{0}$ at $t=0$ is given by

$$
N-N_{\mathrm{u}}=\left(N_{0}-N_{\mathrm{u}}\right) \exp \left(-\frac{t}{\tau}\right) .
$$

The particle removal efficiency $R=\left(N_{0}-N\right) / N_{0}$ is expressed as

$$
R=R_{\max (\mathrm{I})}\left[1-\exp \left(-\frac{t}{\tau}\right)\right],
$$

where $R_{\max (\mathrm{I})}=\left(N_{0}-N_{\mathrm{u}}\right) / N_{0}$, i.e., the maximum removal efficiency at the slow removal stage.

Figure 5 shows the experimental and theoretical results calculated using Eq. (3) for the removal efficiency at the slow removal stage. Since the experimental results are in agreement with the theoretical ones, the removal efficiency can be characterized by two parameters - maximum removal efficiency $R_{\max (\mathrm{I})}$ and time constant $\tau$ - that vary with the jet flow rate.

Figure 6 shows the two parameters as a function of the jet flow rate. The estimated $R_{\max (I)}$ increases with the jet flow rate, while $\tau$ decreases. These variations can be explained by the fact that the separation strength increases with the jet flow rate.

\subsection{Temperature dependence of dry ice jet}

Figure 7 shows the time courses of the temperature of dry ice jet as a parameter of the jet flow rate. There are two distinct temperature-reduction stages - a slow temperature-reduction stage from room temperature to $-10{ }^{\circ} \mathrm{C}$ and a rapid temperature-reduction stage from -10 to $-70{ }^{\circ} \mathrm{C}$. The dry ice jet became white after the second temperature-reduction stage; this indicates that many agglomerated dry ice particles are produced and ejected. A similar phenomenon has been reported in our previous 
studies $[21,22]$. Further, at higher flow rates, the temperature decreases quickly because a large amount of liquid carbon dioxide is expanded, and the jet flow is cooled efficiently in the ABS tube. Therefore, the dry ice particles are produced more quickly at higher flow rates, and the subsequent agglomeration of the particles is enhanced.

The effects of the temperature of the dry ice jet on the particle removal efficiency are shown in Fig. 8. When the jet temperature is in the range from room temperature to $-70{ }^{\circ} \mathrm{C}$, the particle removal efficiency is approximately $20 \%$ or less. Further, when the temperature reaches approximately $-70{ }^{\circ} \mathrm{C}$, the particle removal efficiency increases rapidly. Even if the temperature does not reach approximately $-70{ }^{\circ} \mathrm{C}$, small primary dry ice particles can be produced. However, the contaminant particles strongly adhering to the surface cannot be removed by the impacts of the small primary dry ice particles. When the jet temperature reaches approximately $-70{ }^{\circ} \mathrm{C}$, many agglomerates of dry ice particles are produced and they collide with the contaminant particles, thereby removing most of the particles adhering to the surface. In this manner, the two stages of the particle removal process-slow and rapid particle removal stages — can be explained well by the variations in the jet temperature.

\subsection{Removal area and frequency at rapid removal stage}

Most of the contaminant particles are removed at the rapid removal stage, and hence, the impact of agglomerates is very important. In this sub-section, we will discuss the removal area caused by the impact of an agglomerate of dry ice particles and the removal frequency in detail. Figure 9 shows a series of microscopic images of the test plate covered with powder particles during the rapid removal stage. The three typical images were taken at intervals of $2 \mathrm{~ms}$ using a high-speed microscope camera. In these images, the dry ice jet flows from left to right with an angle of $\pi / 4$ radian against the surface. The powder particles on the test plate appear white whereas the test plate surface has a black appearance. Further, black spots appear after the particles are removed from the surface by the impact of an agglomerate of dry ice particles. The images show that the number of black spots increased with elapsed time. Since the agglomerates of dry ice particles collided with the surface at a certain angle, the shape of the black spots tended to be elliptical. At the rapid removal stage, the equivalent circle diameter of most of the black spots was less than several hundred micrometers. Further, the mass 
median diameter of the contaminant particles was $3 \mu \mathrm{m}$; thus, many particles could be removed at the impact.

Figure 10 shows the distributions of the equivalent circle diameter of the removal area. These results were obtained from the experiments conducted at low jet flow rates, such as 1.4 and $2.2 \mathrm{~g} / \mathrm{s}$, wherein each removal area could be distinguished. The median values of the distribution were 40 and $25 \mu \mathrm{m}$ at the jet flow rates of 1.4 and $2.2 \mathrm{~g} / \mathrm{s}$, respectively; in other words, the removal area decreases as the jet flow rate increases. These results are in agreement with the fact that smaller agglomerates collide with the surface at higher flow rates. To quantitatively analyze the particle diameter of dry ice particles at low jet flow rates, the dry ice jet at $1.4 \mathrm{~g} / \mathrm{s}$ was also observed by using the high-speed microscope camera. The particle diameter of the agglomerated dry ice was found to be approximately $15 \mu \mathrm{m}$ in equivalent circle diameter. Further, the solid-to-gas mass flow ratio was obtained from the pressure-enthalpy diagram of $\mathrm{CO}_{2}$ using the adiabatic expansion process of liquid $\mathrm{CO}_{2}$; the value was 0.43. The results suggest that the particle diameter of the agglomerated dry ice was smaller than the equivalent circle diameter of the observed removal area, which indicates that the agglomerates deformed and moved during their impacts on the surface at the impinging angle.

The microscopic observations using the high-speed microscope camera also give the removal frequency. When the jet flow rates were 1.4 and $2.2 \mathrm{~g} / \mathrm{s}$, the removal frequencies were 940 and 6780 $\mathrm{Hz} / \mathrm{mm}^{2}$, respectively. The removal frequency can be increased by increasing the concentration and velocity of the agglomerates of dry ice particles; the removal frequency thus increases with the jet flow rate.

Since the particle removal efficiency depends on both the removal area and frequency, the product of these factors should be considered for evaluating the particle removal. The removal area ratio was $0.39\left(=(25 / 40)^{2}\right)$ at the jet flow rate of 2.2 to $1.4 \mathrm{~g} / \mathrm{s}$, while the frequency ratio was $7.2(=6780 / 940)$ under the same conditions. Therefore, the effects of the jet flow rate on the removal area were opposite to those on the removal frequency. In this manner, the experimental results show that since the effects of removal frequency on particle removal are more significant, higher jet flow rates are more effective for the particle removal. 


\subsection{Evaluation of particle removal by dry ice jets}

The particle removal frequency at the rapid removal stage under the conditions of higher jet flow rates is too high to analyze each particle removal even by using a high-speed microscope camera. Hence, we measured the brightness of the images and analyzed the normalized particle removal efficiency $R_{\mathrm{II}}$ from 0 to 1 at each rapid removal stage.

Figure 11 shows the time courses of the normalized particle removal efficiency $R_{\mathrm{II}}$ at the rapid removal stage as a parameter of the jet flow rate. $R_{\mathrm{II}}$ increases with the elapsed time, whereas the removal time needed to reach $R_{\mathrm{II}}=1$ decreases as the jet flow rate increases. When the jet flow rates are higher than $3.3 \mathrm{~g} / \mathrm{s}$, the removal time is less than $0.02 \mathrm{~s}$.

To quantitatively evaluate the particle removal system using dry ice jets, we propose a system parameter $\eta$ that is defined as follows:

$$
\eta=\left(\frac{R_{\mathrm{II50}}^{\prime}}{w}\right)
$$

where $R_{\text {II50 }}^{\prime}$ is the derivative of $R_{\mathrm{II}}$ with respect to time at the median value and $w$ is the jet flow rate.

Figure 12 shows the relationship between this system parameter $\eta$ and the jet flow rate; $\eta$ varies with the jet flow rate and its value increases sharply after a certain jet flow rate is exceeded. However, the increase is limited at higher jet flow rates. Therefore, it is ineffective to excessively increase the jet flow rate. Further, this relationship can be used to determine the optimum jet flow rate for dry ice blasting.

\section{Conclusions}

In this study, we have investigated the removal process of fine particles adhering to the test plate using impinging dry ice jets. Further, by conducting quantitative analyses of the particle removal efficiency as a function of time elapsed and the variations in the temperature of the dry ice jet, the key factors for the particle removal processes were analyzed. The conclusions of the study can be summarized as follows: 
(1) The particle removal process consists of two stages-slow removal stage and rapid removal stage - that are related to variations in the temperature of the dry ice jet.

(2) The slow removal stage occurs from room temperature to $-70{ }^{\circ} \mathrm{C}$, whereas the rapid removal stage occurs at approximately $-70{ }^{\circ} \mathrm{C}$; at this temperature, many agglomerates of dry ice particles are produced, and they collide with the contaminant particles.

(3) The particle removal efficiency at the slow removal stage can be explained by a theoretical equation with two parameters.

(4) Most of the contaminant particles on the surface are removed at the rapid removal stage; here, the key factors are the removal area due to the impact of an agglomerate of dry ice particles and the removal frequency. Moreover, as the jet flow rate increases, the removal area decreases, but the removal frequency increases. For the particle removal, the removal frequency is more significant than the removal area. Therefore, high jet flow rates are more effective for particle removal.

(5) A system parameter defined as the ratio of the particle removal rate to the jet flow rate can be used to quantitatively evaluate the particle removal and to determine the optimum jet flow rates for dry ice blasting.

Acknowledgement: This research was supported in part by the Global COE Program "International Center for Integrated Research and Advanced Education in Materials Science" (No. B-09) of the Ministry of Education, Culture, Sports, Science and Technology (MEXT), Japan, administrated by the Japan Society for the Promotion of Science.

\section{References}

[1] H. Masuda, K. Gotoh, H. Fukada, Y. Banba, The removal of particles from flat surfaces using a high-speed air jet, Adv. Powder Technol. 5 (1994) 205-217.

[2] Y. Otani, H. Emi, T. Morizane, J. Mori, Removal of fine particles from wafer surface by pulse air jets, Kagaku Kogaku Ronbunshu 19 (1993) 114-119. 
[3] Y. Otani, N. Namiki, H. Emi, Removal of fine particles from smooth flat surfaces by consecutive pulse air jets, Aerosol Sci. Technol. 23 (1995) 665-673.

[4] K. Gotoh, S. Takebe, H. Masuda, Effect of surface material on particle removal using high speed air jet, Kagaku Kogaku Ronbunshu 20 (1994) 685-692.

[5] K. Gotoh, M. Kida, H. Masuda, Effect of particle diameter on removal of surface particles using high speed air jet, Kagaku Kogaku Ronbunshu 20 (1994) 693-700.

[6] K. Gotoh, S. Takebe, H. Masuda, Y. Banba, The effect of humidity on the removal of fine particles on a solid surface using high-speed air-jet, KONA Powder and Particle 13 (1995) 191203.

[7] G. T. Smedley, D. J. Phares, R. C. Flagan, Entrainment of fine particles from surfaces by gas jets impinging at normal incidence, Exp. Fluids 26 (1999) 324-334.

[8] G. T. Smedley, D. J. Phares, R. C. Flagan, Entrainment of fine particles from surfaces by gas jets impinging at oblique incidence, Exp. Fluids 30 (2001) 135-142.

[9] S. A. Hoenig, Cleaning surfaces with dry ice, Compressed Air Magazine 91 (1986) 22-25.

[10] R. Sherman, Carbon dioxide snow cleaning, Particulate Sci. Technol. 25 (2007) 37-57.

[11] D. Jackson, B. Carver, Today's forecast: it looks like snow, Precision Cleaning 8 (1999) 16-29.

[12] Y. Kousaka, K. Okuyama, Y. Endo, Re-entrainment of small aggregate particles from a plane surface by air stream, J. Chem. Eng. Jpn. 13 (1980) 143-147.

[13] H-C. Wang, Effects of inceptive motion on particle detachment from surfaces, Aerosol Sci. Technol. 13 (1990) 386-393.

[14] C. J. Tsai, D. Y. H. Pui, B. Y. H. Liu, Particle detachment from disk surfaces of computer disk drives, J. Aerosol Sci. 22 (1991) 737-746.

[15] S. Matsusaka, H. Masuda, Particle reentrainment from a fine powder layer in a turbulent air flow, Aerosol Sci. Technol. 24 (1996) 69-84.

[16] I. Adhiwidjaja, S. Matsusaka, H. Tanaka, H. Masuda, Simultaneous phenomenon of particle deposition and reentrainment: effects of surface roughness on deposition layer of striped pattern, Aerosol Sci. Technol. 33 (2000) 323-333. 
[17] W. Theerachaisupakij, S. Matsusaka, Y. Akashi, H. Masuda, Reentrainment of deposited particles by drag and aerosol collision, J. Aerosol Sci. 34 (2003) 261-274.

[18] C. Toscano, G. Ahmadi, Particle removal mechanisms in cryogenic surface cleaning, J. Adhesion 79 (2003) 175-201.

[19] S. Banerjee, A. Campbell, Principles and mechanisms of sub-micrometer particle removal by $\mathrm{CO}_{2}$ cryogenic technique, J. Adhesion Sci. Technol. 19 (2005) 739-751.

[20] E. A. Swain, S. R. Carter, S. A. Hoenig, Carbon dioxide snow agglomeration and acceleration, U.S. Patent (1992) 5125979.

[21] Y. H. Liu, H. Maruyama, S. Matsusaka, Agglomeration process of dry ice particles produced by expanding liquid carbon dioxide, Adv. Powder Technol. 21 (2010) 652-657.

[22] Y. H. Liu, H. Maruyama, S. Matsusaka, Effect of particle impact on surface cleaning using dry ice jet, Aerosol Sci. Technol. 45 (2011) 1519-1527. 


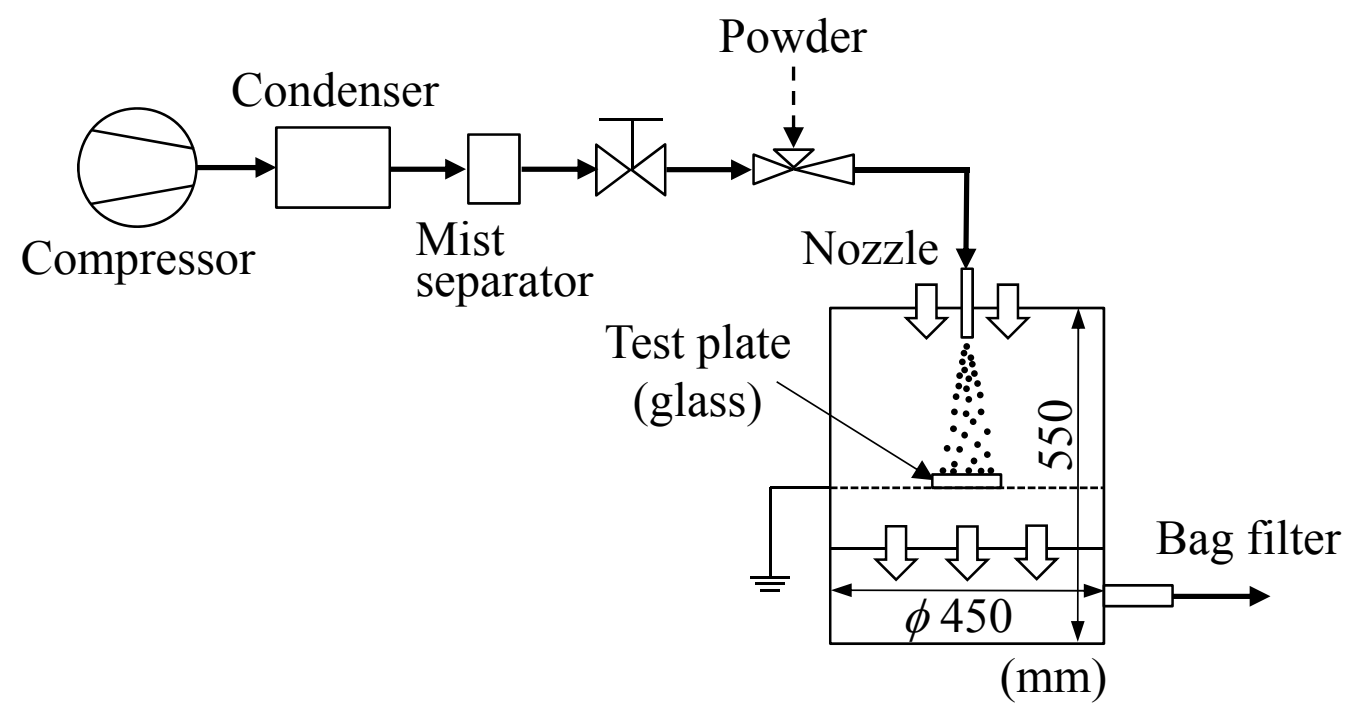

Fig. 1. Preparation of test plate. 


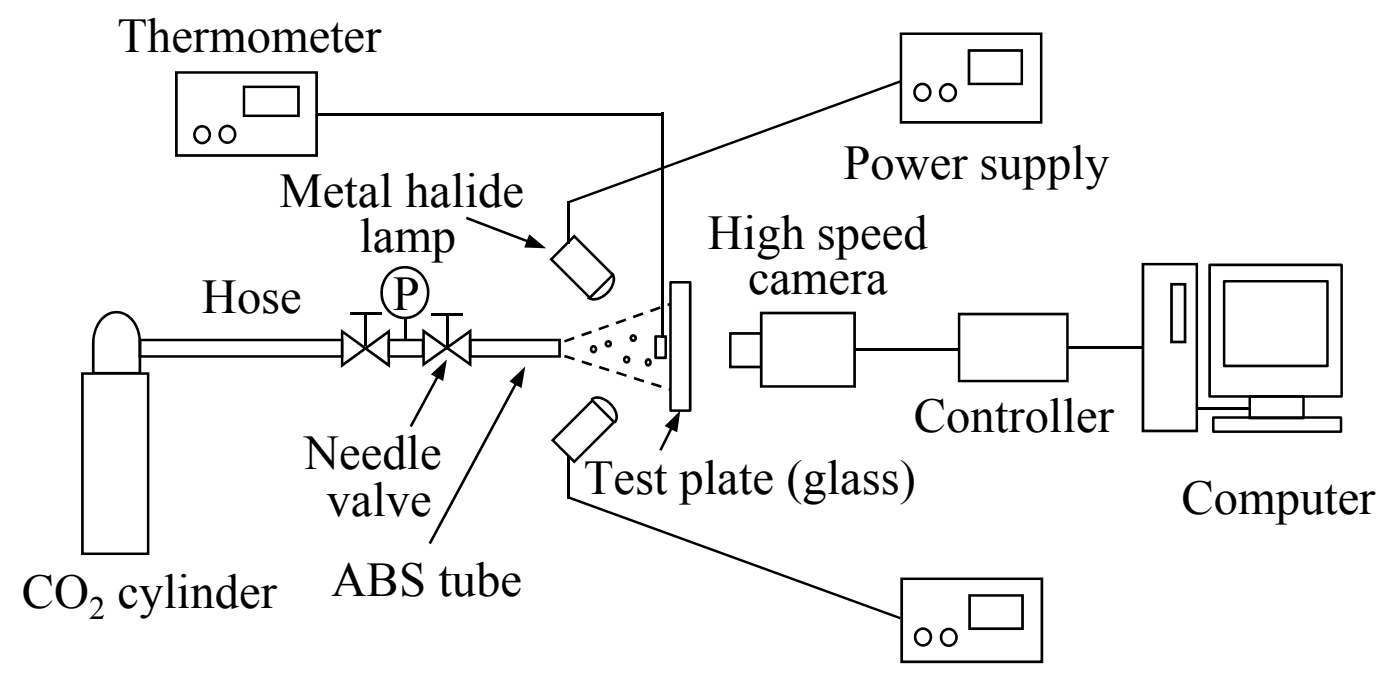

Fig. 2. Experimental apparatus. 
(a) Jet flow rate: $1.4 \mathrm{~g} / \mathrm{s}$
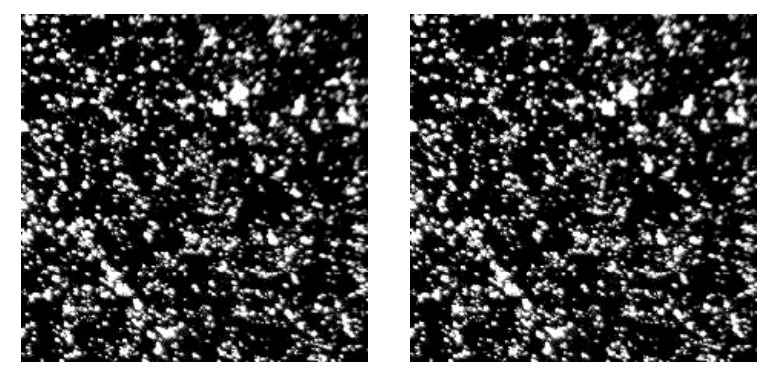

$0 \mathrm{~s}$

$8.340 \mathrm{~s}$

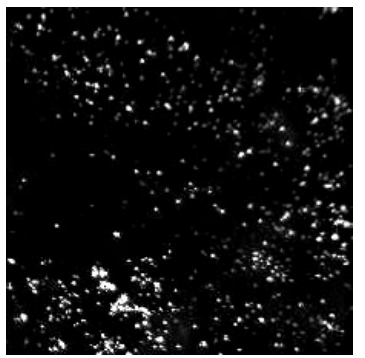

$8.436 \mathrm{~s}$

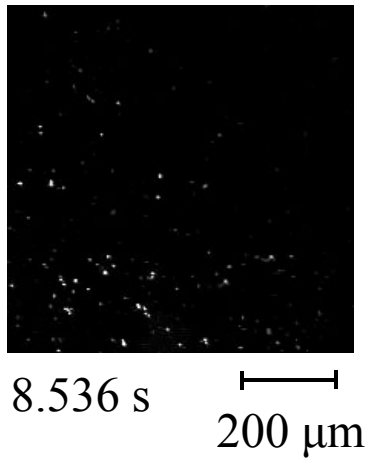

(b) Jet flow rate: $4.9 \mathrm{~g} / \mathrm{s}$
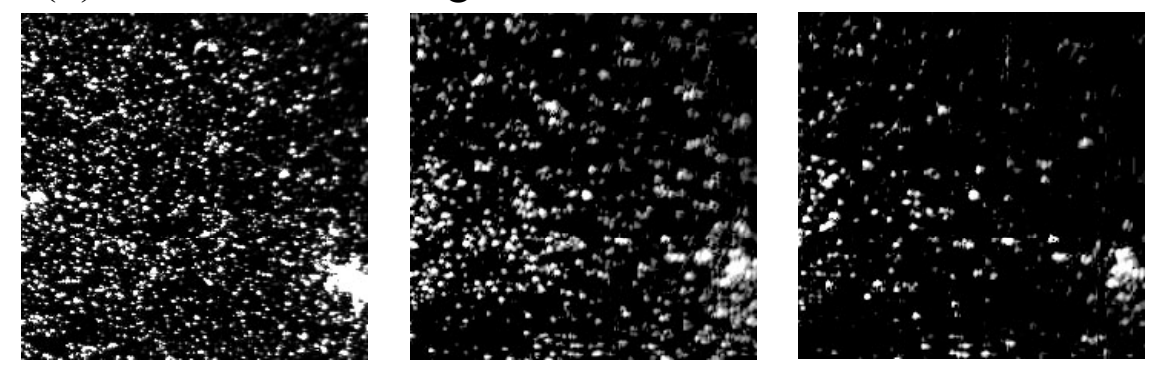

$0 \mathrm{~s}$

$3.224 \mathrm{~s}$

$3.248 \mathrm{~s}$

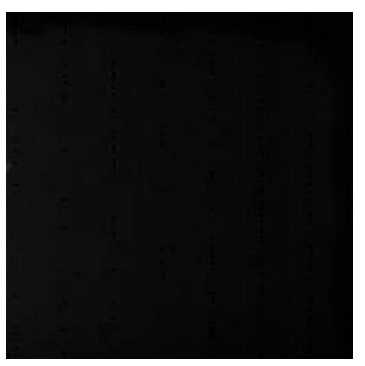

$3.272 \mathrm{~s}$

Fig. 3. Micrographs of particle removal by dry ice blasting (frame rate: $250 \mathrm{fps}$ ). 


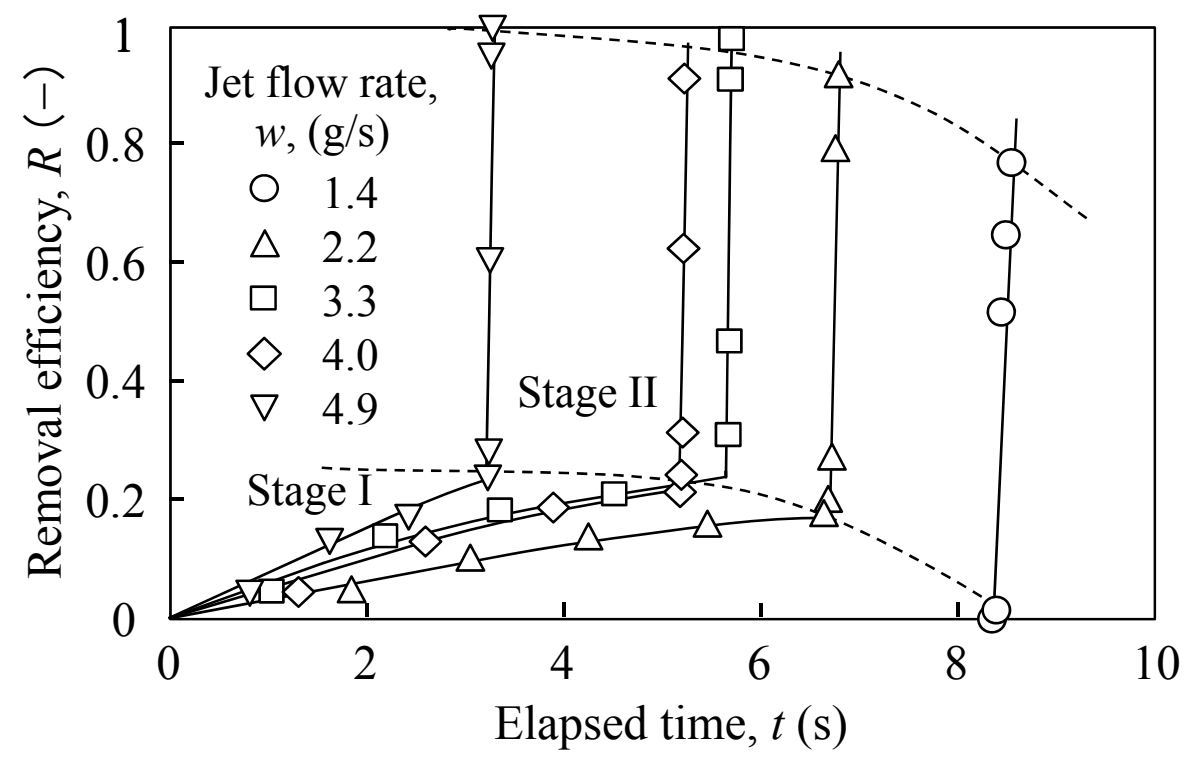

Fig. 4. Time course of particle removal efficiency. 


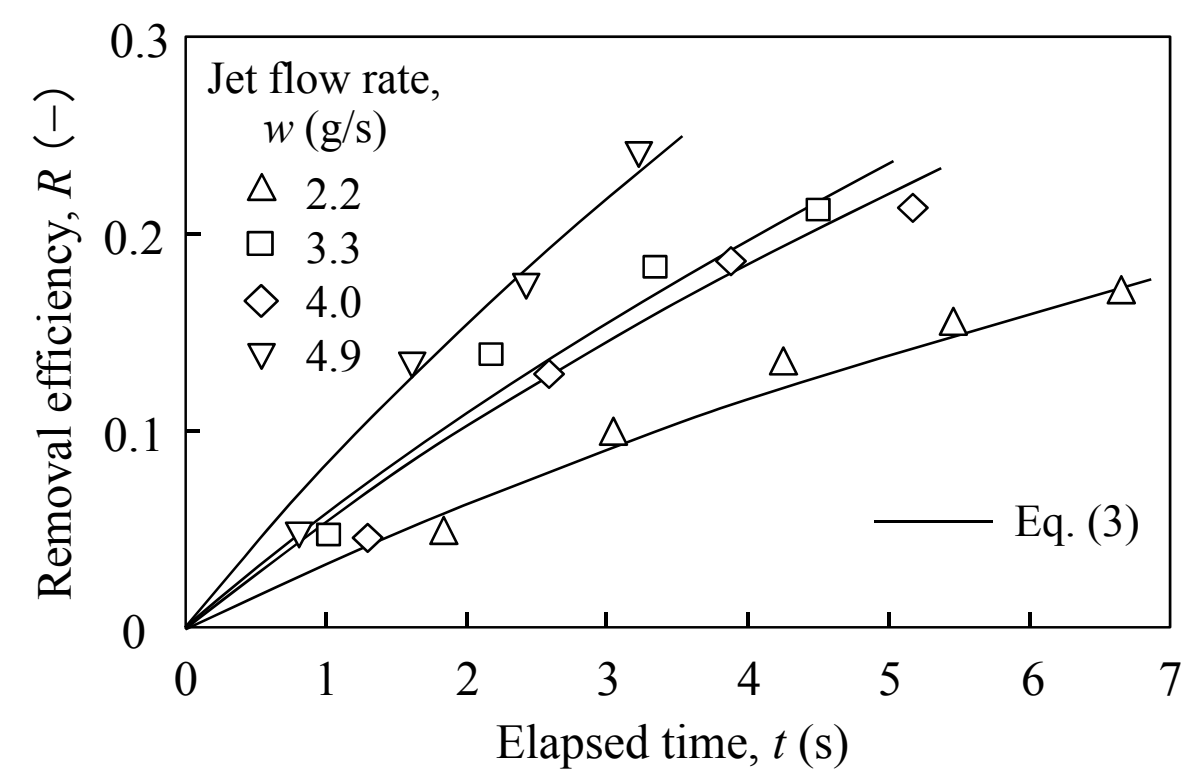

Fig. 5. Theoretical estimation of particle removal efficiency. 

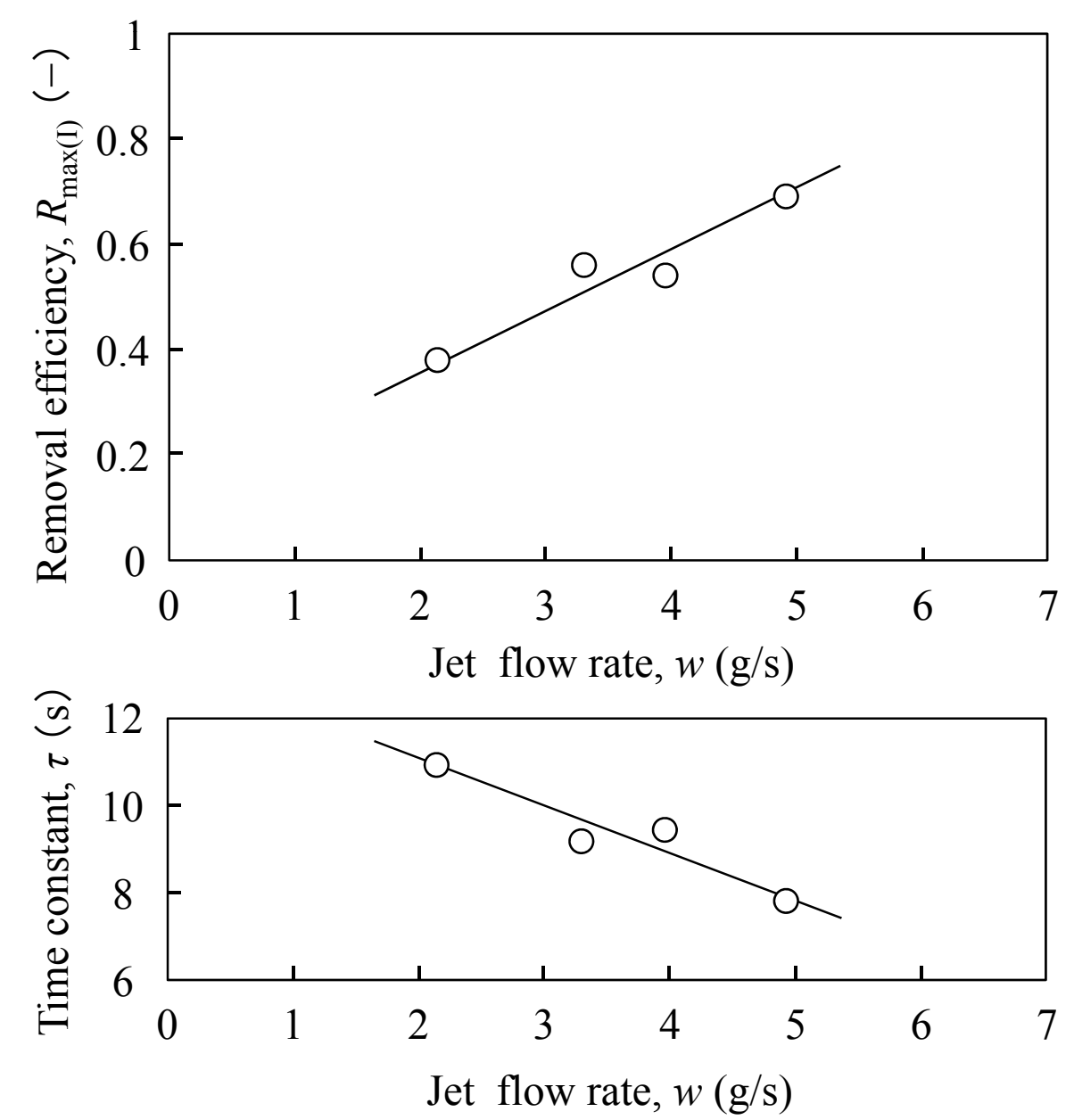

Fig. 6. Values of fitting parameters $R_{\max (\mathrm{I})}$ and $\tau$ in Eq. (3). 


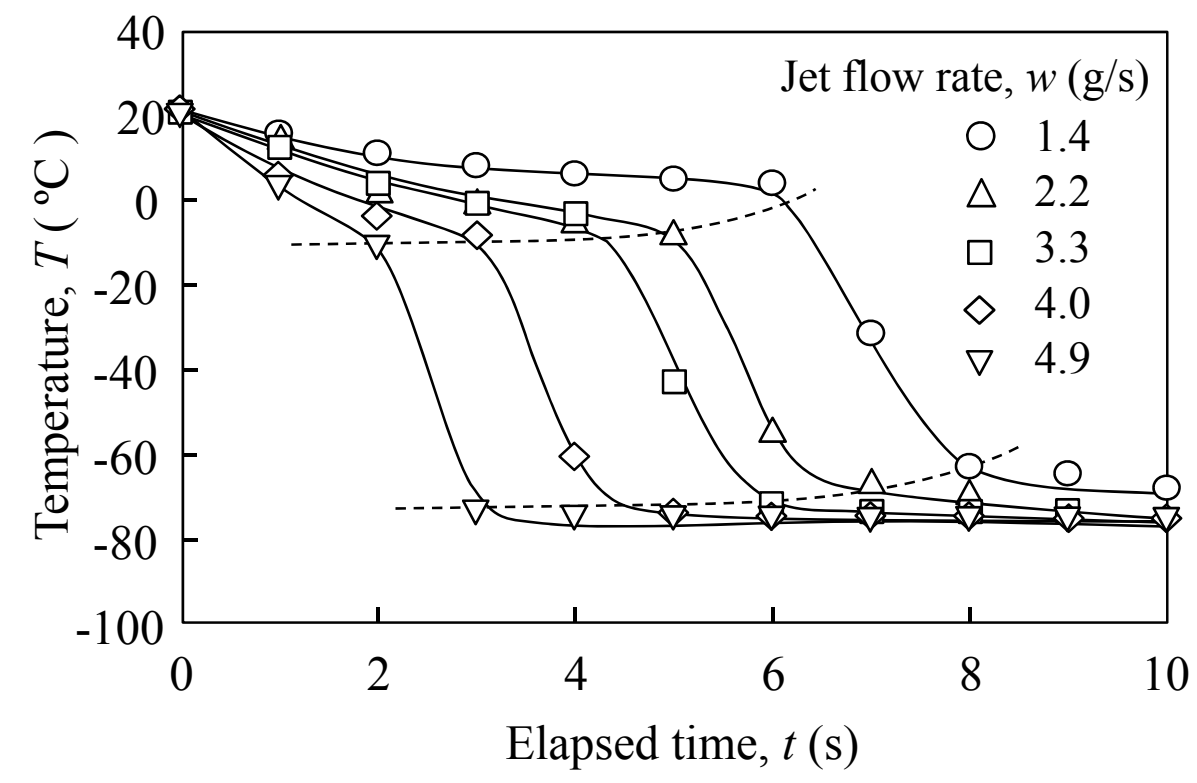

Fig. 7. Time courses of temperature of dry ice jet. 


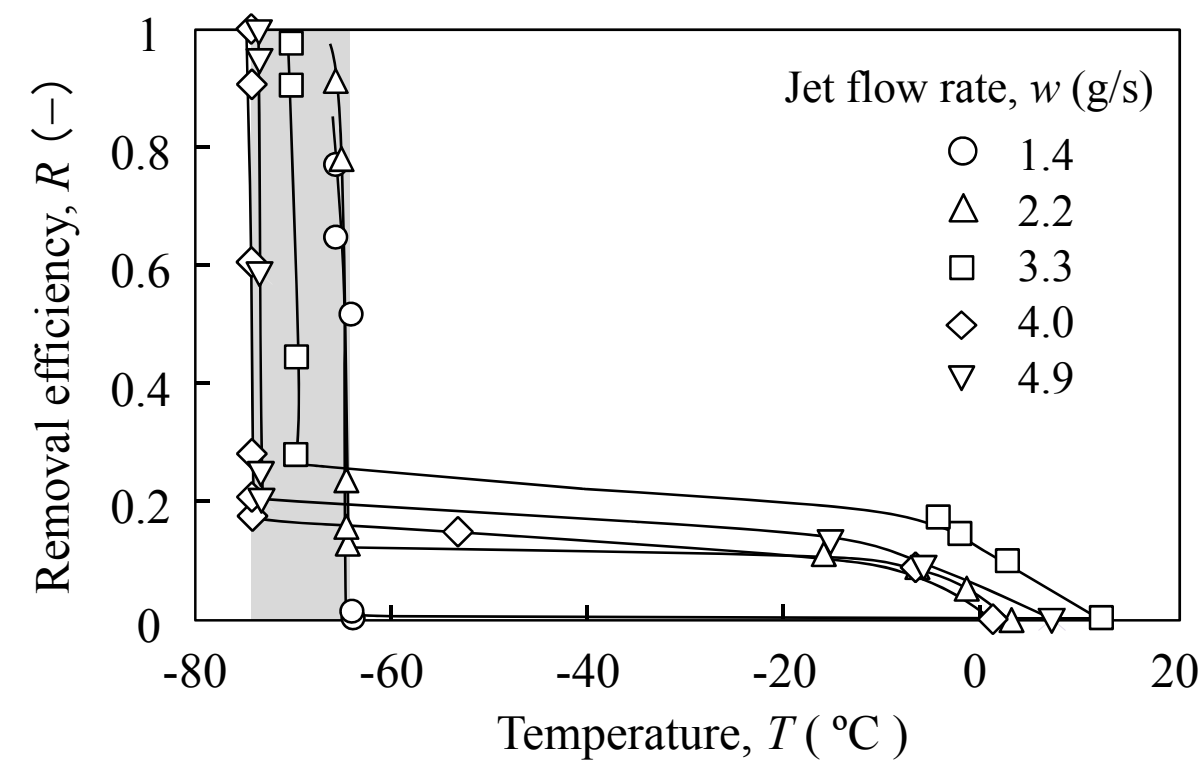

Fig. 8. Relationship between particle removal efficiency and jet temperature. 


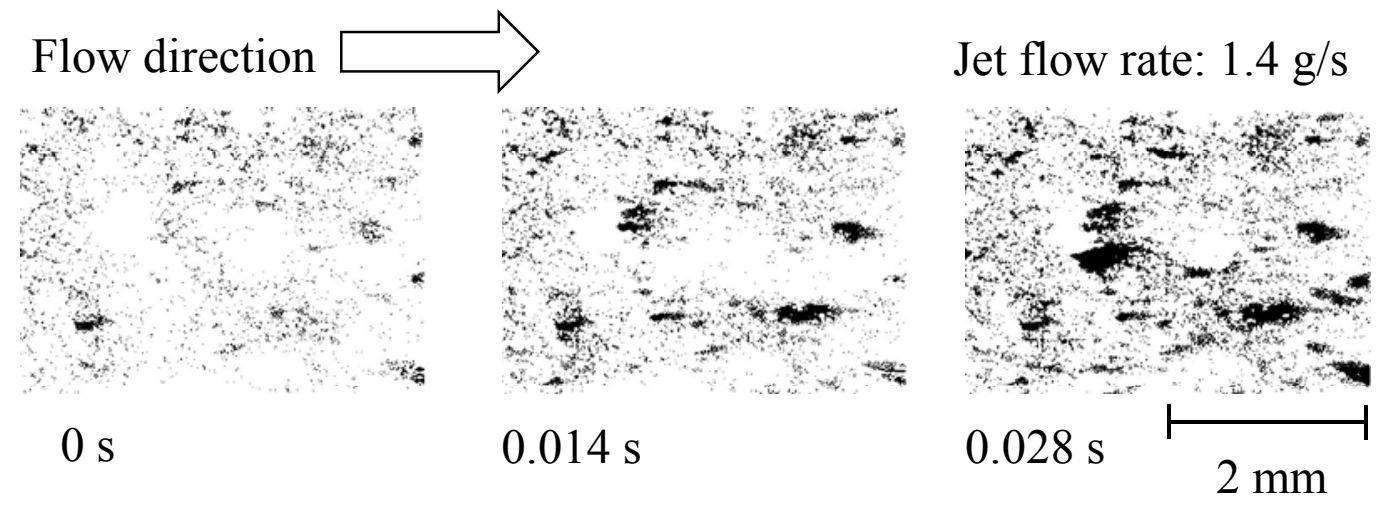

Fig. 9. Micrographs of particle removal by dry ice impact at rapid removal stage (frame rate: $500 \mathrm{fps}$ ). 


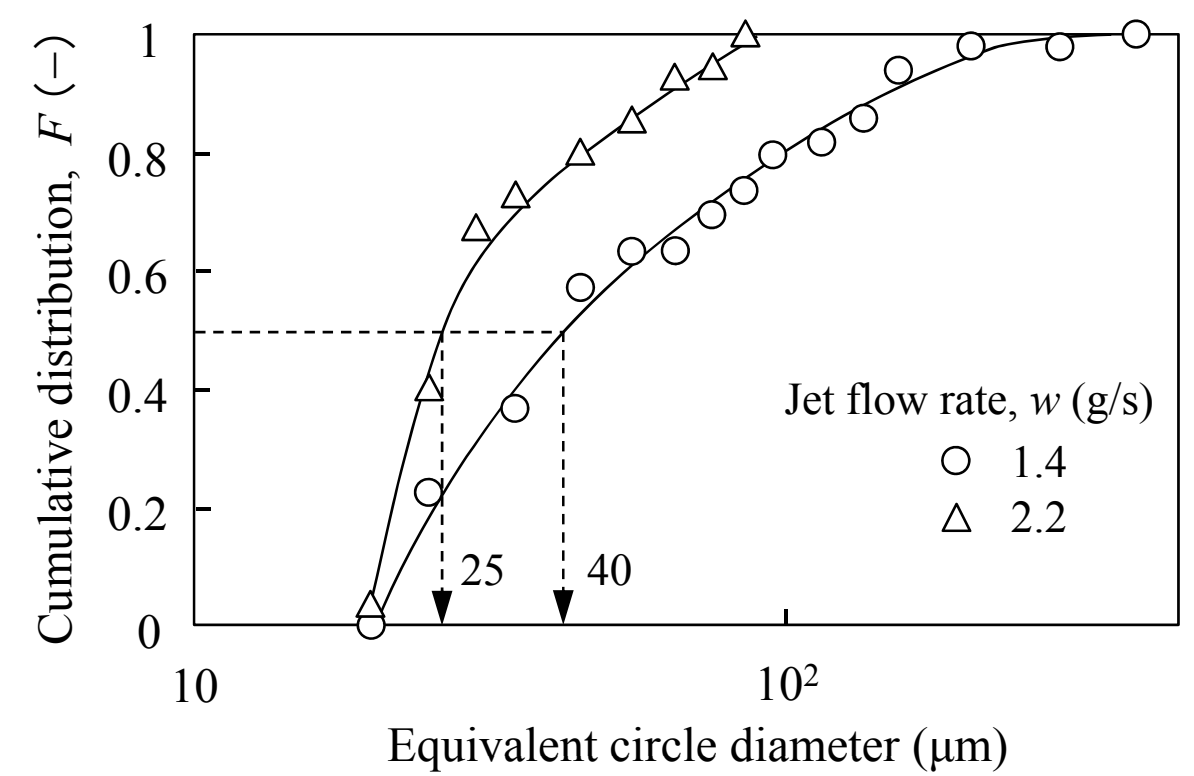

Fig. 10. Cumulative distribution of removal area at rapid removal stage. 


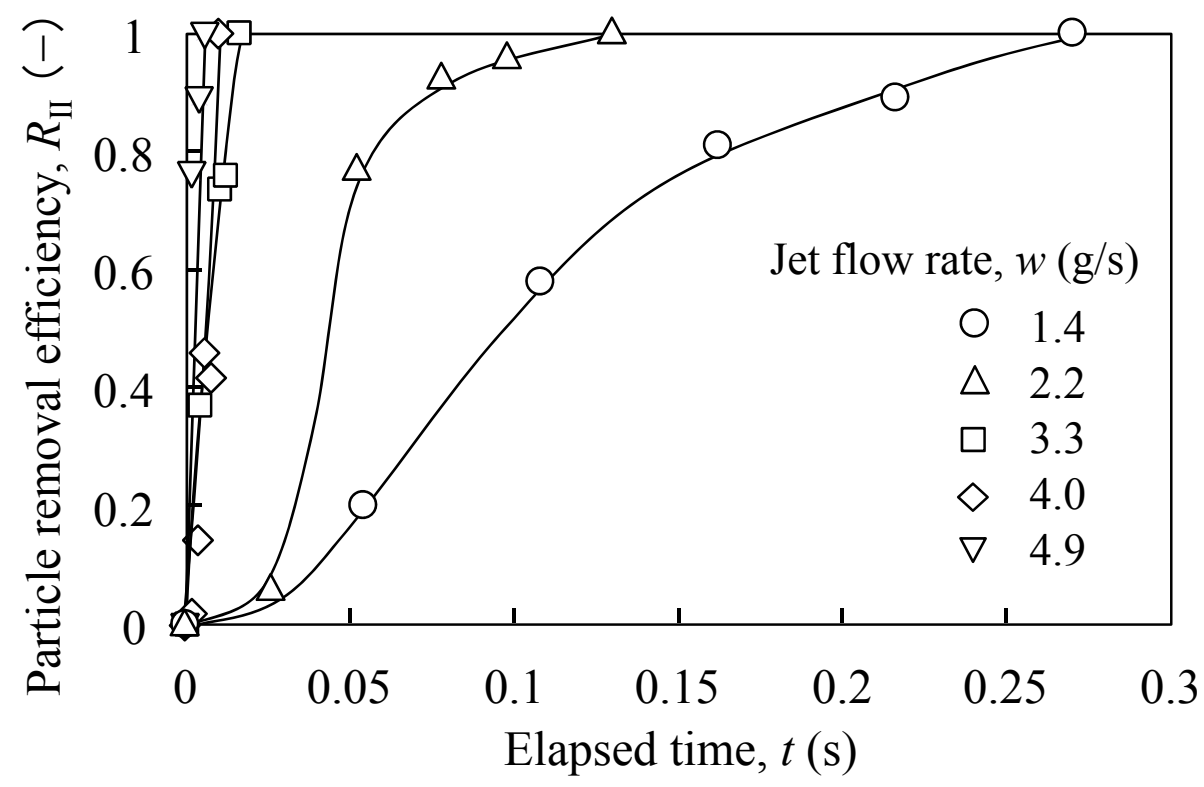

Fig. 11.Normalized particle removal efficiency at rapid removal stage. 


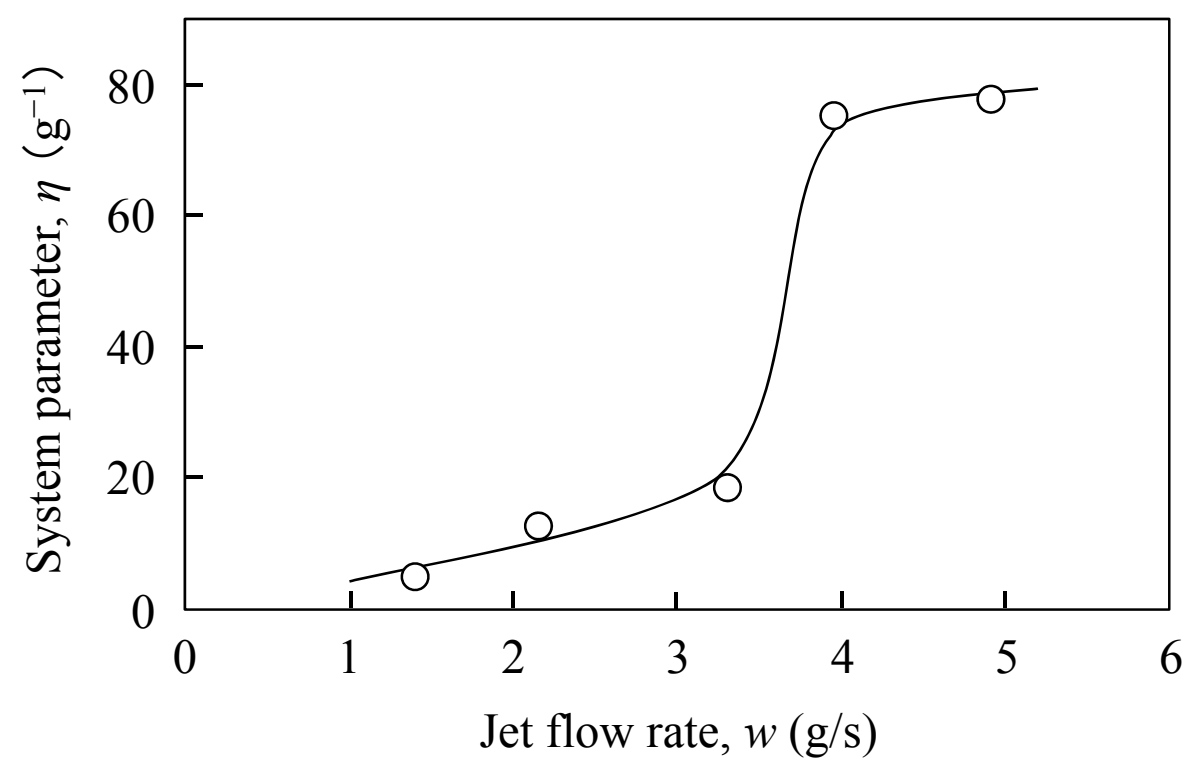

Fig. 12. Impact efficiency of removal process. 